\title{
In Situ Testing of Ground Support Performance Under Strong Dynamic Loading
}

\author{
D.P. Heal School of Civil and Resource Engineering, University of Western Australia \\ M.R. Hudyma, C.C. Langille, Y. Potvin Australian Centre for Geomechanics, Australia \\ R.J. Butcher, R. Ball, B. Hartmann Lightning Nickel Pty Ltd, Australia
}

In the past, simulated rockbursts using blasting have been carried out to assess the relative performance of bonded surface support systems (Espley et al. 2002, Archibald et al. 2003), study the response of rockbolts to dynamic loading (Haile et al. 2001, Tannant et al. 1994a, 1994b and 1995) and for broad ground motion studies (Hagan et al. 2001). Two series of simulated rockbursts have been carried out at the Long Shaft mine near Kambalda, Western Australia, with a view to testing the in situ performance of four integrated ground support and reinforcement systems when subjected to strong ground motion. The experiments are part of a wider series of tests being undertaken by the Australian Centre for Geomechanics at a number of seismically active Western Australian underground mines, with the aim of testing the in situ performance of a number of standard and innovative ground support systems under strong dynamic loading conditions. The testing includes ground motion measurement with a 16 channel Impulse seismic monitoring system, three-dimensional photogrammetric imaging using the CSIRO developed Sirovision package, crack monitoring using a borehole camera, digital video camera filming and extensive manual measurements and mapping (Heal et al. 2004). This paper discusses the methodology involved in carrying out these simulated rockbursts and also presents the issues that will be addressed with the view to ultimately improve our understanding of ground support system performance under strong dynamic loading conditions. The preliminary results from testing at Long Shaft are also presented.

\section{INTRODUCTION}

As Western Australian underground mines reach increasingly greater depths, the problems of mining induced seismicity and rockbursting have necessitated the use of ground support and reinforcing systems which are capable of withstanding strong dynamic loads. There is a clear need to optimise the design of such dynamic support systems in mines through developing a better understanding of their behaviour under strong dynamic loading.

Previous ground support testing programs involving the use of drop weights or laboratory simulations have provided important information on theload-deformation characteristics of individual support elements under dynamic loading conditions. These tests do not, however, account for rock-support interaction or the influence of local rockmass conditions. The study of in situ rockburst damage can only be carried out after the fact. When relying on such data, researchers have no control over the location and nature of the seismic source, often leading to ambiguous results. By simulating rockburst damage using blasting, it is possible to investigate the in situ performance of complete ground support systems (incorporating reinforcing, retaining and surface support elements) due to a range of measurable dynamic loads.

By simulating rockbursts at several mines, the research will investigate the influence of rockmass discontinuities, rockmass damage, and stress conditions on rockburst damage, as well as the influence of support and reinforcement systems to reduce displacement and damage when subjected to dynamic loads. Some specific issues that can be addressed at individual mines include:

- How effective are a mine's standard support systems under dynamic loading conditions?

- What is the effect of support and rockmass deterioration on the performance of the support system?
- Is typical Western Australian support (e.g. split sets) sufficient if the support density is increased, when coupled with strong surface support (e.g. mesh reinforced shotcrete)?

- At what point (or level of dynamic loading) are yielding reinforcing elements required (e.g. cone bolts and debonded cables)?

- Is mesh strapping a suitable substitute for shotcrete or fibrecrete?

- What is the effect of bolt spacing on support system performance?

- What amount of deformation is permissible for the support system to remain functional?

- Could thin spray-on liner products provide cost and safety improvements in seismically active Western Australian mines?

Combined with the results of drop weight testing, case studies and laboratory simulations, this research will contribute to the development of more robust ground support design procedures, leading to improvements in safety and potentially cost efficiency in areas of underground mines affected by rockbursting.

\section{TESTING METHODOLOGY}

\subsection{Test Layout}

The simulated rockburst experiments are conducted by blasting adjacent to the walls of disused excavations. Test sites must be located near an intersection to allow drilling of blastholes parallel to the test wall. The excavations chosen are preferably located in highly stressed areas of the mine, where pre-existing stress driven rockmass damage surrounding excavations will allow for large dynamic loading upon ground support systems subjected to strong ground motion. Typically, three blastholes are drilled parallel to and $5 \mathrm{~m}$ from the test wall at each site, as shown in Figures 1 and 2 . 


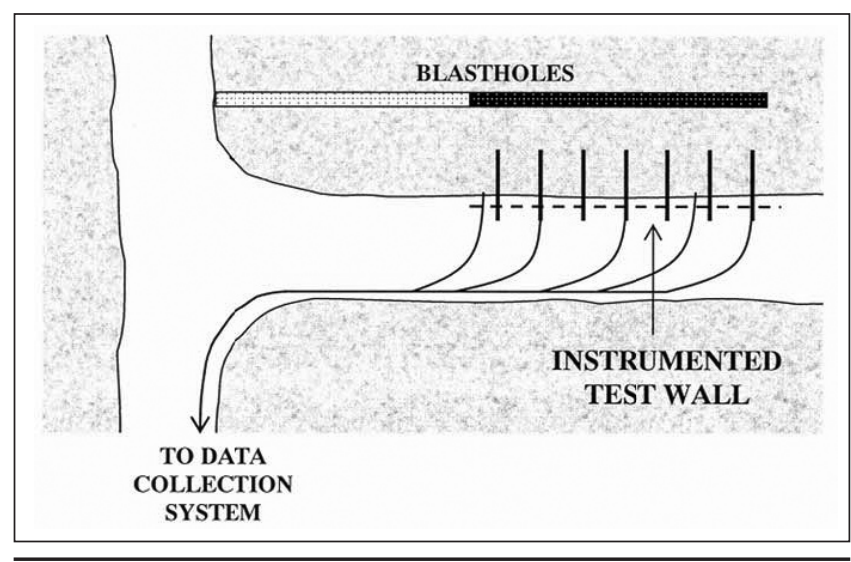

FIG. 1 Conceptual layout of simulated rockburst experiments

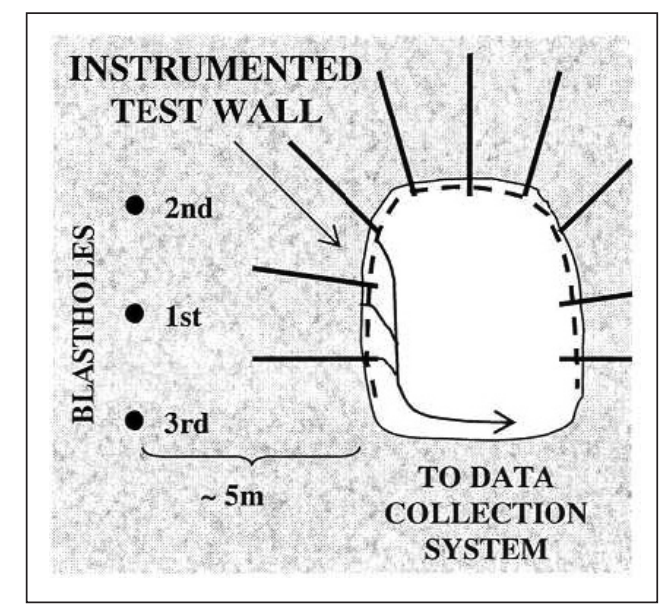

FIG. 2 Conceptual cross-sectional view of simulated rockburst experiments

A distance of $5 \mathrm{~m}$ is used to attempt to limit the influence of explosive gases generated during blasting on the test wall (Hagan et al. 2001).

Each blasthole is separately charged and detonated to allow successively larger dynamic loading upon the test wall. The central hole is used firstly to generate a small calibration blast using a single primer (to ensure the instrumentation is functional) then charged again (the first simulated rockburst) with an aim to generate a peak particle velocity (PPV) of up to $0.5 \mathrm{~m} / \mathrm{s}$. The top blasthole (the second simulated rockburst) is charged to generate a PPV of up to $1.5 \mathrm{~m} / \mathrm{s}$ on the test wall. The bottom hole (the third simulated rockburst) is charged with a view to achieve a PPV of up to $5 \mathrm{~m} / \mathrm{s}$. Further particulars of the blasting are discussed in Section 2.4.

Series of simulated rockbursts will be undertaken at a few sites within each mine to allow testing of a range of ground support systems under varied rockmass conditions. Freshly and previously installed ground support systems will be tested at different sites, to investigate the effect of loss of support functionality due to deterioration from corrosion, past dynamic loading and deteriorated ground conditions. For sites with newly installed support, two ground support systems are installed side by side to allow direct physical comparison in the same rockmass conditions. A $5 \mathrm{~m}$ length of each support system is installed, giving the test wall a total length of $10 \mathrm{~m}$.

\subsection{Instrumentation and Equipment}

Ground motion monitoring at each site is conducted using $14 \mathrm{~Hz}$ SM6 geophones connected to a 16 channel Impulse seismic monitoring system. The Impulse system allows a maximum sampling rate of $10 \mathrm{kHz}$ per channel, which is adequate to prevent aliasing of waveforms, considering the maximum frequency of ground motion expected to be generated by the blasting is not more than $1 \mathrm{kHz}$. Two triaxial geophones are installed in $2 \mathrm{~m}$ long $64 \mathrm{~mm}$ diameter blastholes, drilled perpendicular to the test wall. The triaxial geophones provide an indication of the characteristics of the ground motion generated by each blast, as well as allow comparison between the PPV in the intact rock to the PPV at the surface of the excavation. A further 6 horizontal uniaxial geophones are mounted on the surface of the test wall. The remaining 4 channels are used for horizontal uniaxial geophones end-mounted on rockbolts. It is envisaged that data from these rockbolt geophones will provide insight into the dynamic response of the different rockbolt types as well as estimates of the degree of interaction between these elements and the rockmass. All geophones are mounted using two-part epoxy resin. Protection of cables during blasting is important for the successful use of the monitoring system for simulated rockbursts. Experience from the first series of simulated rockbursts, however, indicated that while some cables can be expected to be severed by flyrock from a blast, transmission of the shock wave data occurs before breakage, allowing waveform data to be recorded.

As the maximum input voltage of the Impulse seismic monitoring system is $10 \mathrm{~V} /(\mathrm{m} / \mathrm{s})$, and the response of the SM6 geophones is approximately $28 \mathrm{~V} /(\mathrm{m} / \mathrm{s})$, some degree of geophone damping is required to prevent "clipping" of waveforms during blasting. By incorporating a 25-30 $\Omega$ shunt resistor into each geophone circuit, the geophone response can be altered to around $2 \mathrm{~V} /(\mathrm{m} / \mathrm{s})$, which allows the Impulse to record ground motions of up to around $5 \mathrm{~m} / \mathrm{s}$, suitable for the largest blast.

A number of $46 \mathrm{~mm}$ observation holes are drilled perpendicular to the test wall for borehole camera observations. These measurements allow investigation of the degree and nature of rockmass fracturing before and after each blast. The borehole camera can also be used inside split set friction bolts to attempt to identify slip or plastic yield along their length.

Extensive mapping of each test site before and after each blast is carried out using Sirovision, a three dimensional photogrammetry system developed by the CSIRO and designed primarily for structural mapping of underground or open cut rock faces (CSIRO 2003). Sirovision allows the generation of fully digitised three dimensional images from stereo pairs of photographs, when accurate survey support is available. As well as mapping, images generated before and after successive blasts are used to identify areas of rock bulking or ejection, accurately measure deformation of surface support and measure the displacement of rockbolt plates and ends. These measurements contribute greatly to the qualitative and quantitative assessment of ground support system performance. In addition, the Sirojoint module allows the user to accurately measure the parameters defining discontinuities in a rockmass and analyse the structure of a rockmass by using three-dimensional images (CSIRO 2003). An example of a three dimensional image generated from a high resolution digital image is shown in Figures 3, 4 and 5.

The Sirovision software uses two digital images of known camera separation to generate a ranged three-dimensional image. Accurately surveyed points visible on the images can then be used to translate the ranged image into a true threedimensional image, relative to the mine's co-ordinate system. 


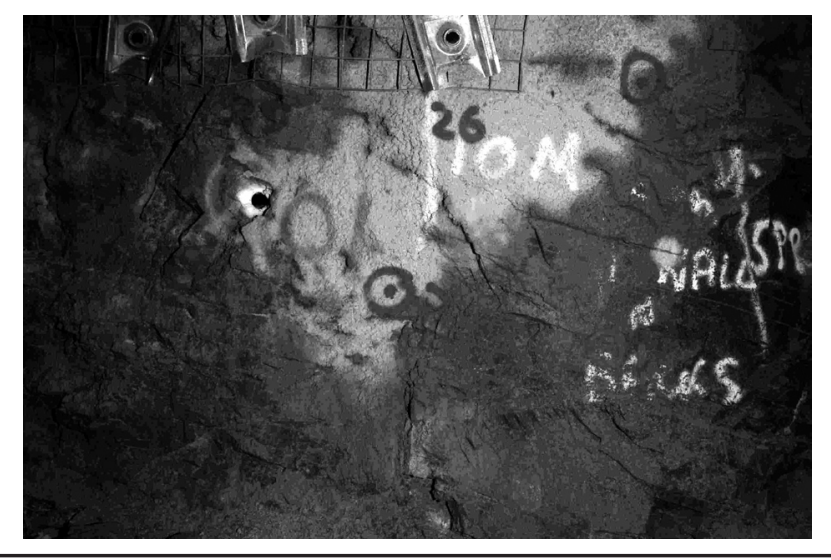

FIG. 3 One of two high resolution digital images used by the Sirovision software to generate the three-dimensional point cloud in Fig. 4 and the three-dimensional image in Fig. 5

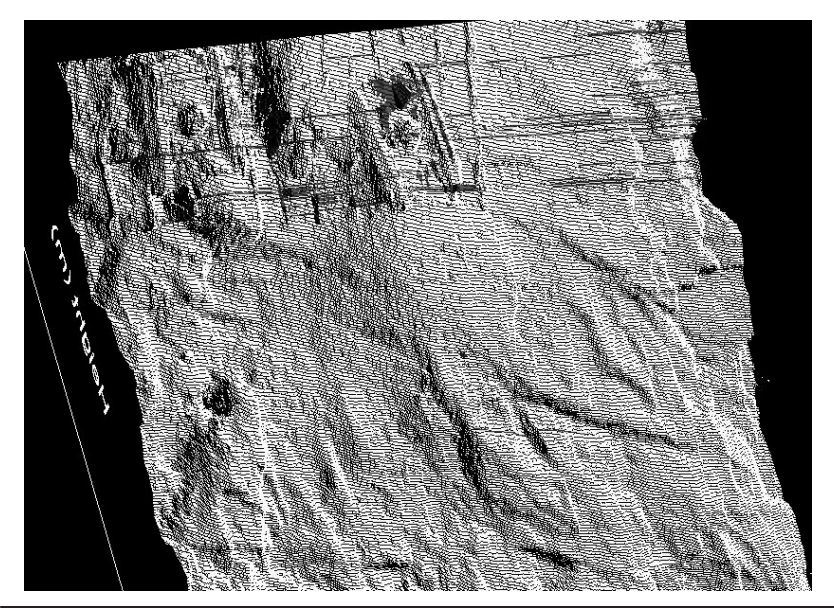

FIG. 4 A three-dimensional point cloud generated using the digital image in Fig. 3

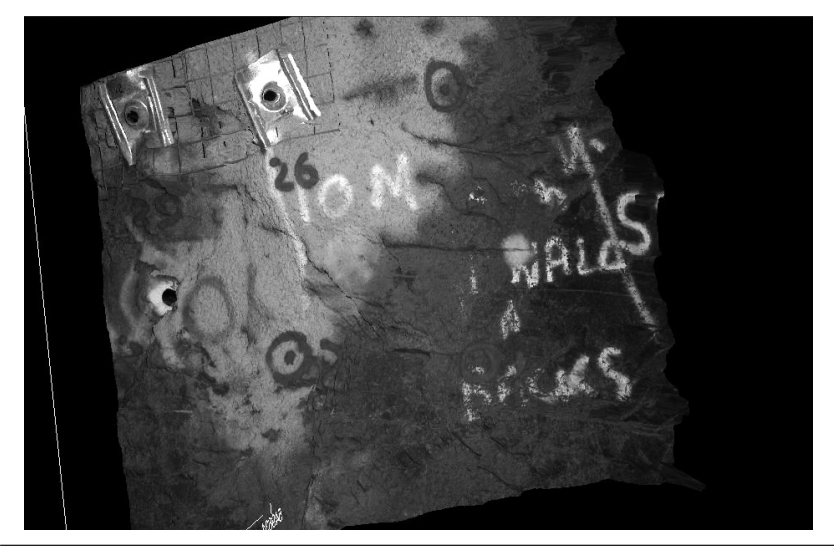

FIG. 5 A three-dimensional image generated from the three-dimensional point cloud in Fig. 4 and digital image in Fig. 3

Four numbered points in Figure 3 were used to orient the three-dimensional image in Figure 5 in the mine specific coordinate system.

All simulated rockbursts are recorded using a Canon MV750i digital video camera, set up at sufficient distance from the test wall to avoid damage due to ground shaking or ejected rock or support fragments. The camera is used to maintain a permanent record of each simulated rockburst, as well as assessment of the nature and velocity of ejected rock and support fragments during the experiments. In some blasts, rockmass damage due to the simulated rockburst can be observed before dust obscures the video record.

\subsection{Measurements and Observations}

A combination of the methods described in the previous section and manual techniques is used to assess the performance of each ground support system when subjected to each successively larger dynamic load. Each section below summarises the measurements and observations taken as well as the methods used.

\subsubsection{Geotechnical properties of the test site}

Conventional methods such as geotechnical face mapping of the test wall and nearby stress measurements are used. Additionally, CSIRO Sirovision is used to provide a photographic record of the test site at all stages of blasting and also to allow analysis of rockmass structure using the Sirojoint module.

\subsubsection{Ground motion}

Peak particle velocity is measured using both surface mounted uniaxial geophones and borehole mounted triaxial geophones. The Impulse seismic monitoring system software is used to download raw waveform data from the unit, generate waveforms based on the damping parameters of the geophones and for exporting the processed waveforms for further analysis.

\subsubsection{Location and behaviour of rock fractures}

A borehole camera is used before and after each successive blast to locate existing fractures or jointing and then to assess the influence of the dynamic load on rockmass behaviour. It is considered that measurement of the location of new fractures or the behaviour of existing fractures, together with accurate measurement of ground motion, can allow the estimation of dynamic load (in terms of $\mathrm{kJ} / \mathrm{m}^{2}$ ) on the ground support system.

\subsubsection{Identification and accurate measurement of areas of rock bulking and ejection}

Analysis of the three dimensional images generated by Sirovision allows the determination of volumes of ejected or bulked rock over the entire test wall. A comparison of the digital models created by the software before and after each successive blast also aids greatly in quantitative damage assessment. The high resolution digital camera used in these experiments allows generation of extremely detailed three dimensional images (for example Figures 4 and 5) which provide a permanent record of the test site following each simulated rockburst.

\subsubsection{Measurement of ejection velocity and maximum displacement of rockmass and support}

Three methods are available for these measurements. Firstly, calculation of ejection velocity is possible from digital video camera images, provided the position and orientation of the camera are considered. One problem with this method is that the camera recording frame rate must be lowered if lighting is inadequate, which is often the case in underground mines. Secondly, maximum displacement of the test wall surface or monitored rockbolts may be estimated from integration of velocity waveforms. The final method involves back calculating projectile ejection velocity based on its final position on the test site floor (ballistics), however this method has inherent assumptions and is likely to be inaccurate.

\subsubsection{Source parameters of simulated rockbursts}

All mines at which simulated rockburst testing are undertaken have mine-wide seismic monitoring systems, which 
can be used to assess the source parameters of each simulated rockburst blast. Seismic sensor saturation on the mine-wide seismic system was found to be an issue at the Long Shaft test sites. This affects source parameter calculations such as energy release and magnitude, however if more distant seismic sensors record the blasting, these issues can be overcome.

\subsubsection{Response of reinforcing and retaining elements to dynamic loading}

Uniaxial geophones end-mounted on rockbolts allow direct measurement of peak particle velocity induced in the rockbolt steel as a result of the dynamic load caused by blasting. This allows estimates of the degree of rockbolt coupling with the rockmass, the dynamic stress induced in the rockbolt and analysis of the frequency response of the rockbolt. The response of split set friction bolts can also be examined through the use of a borehole camera, whereby failure or yield of the split set can potentially be assessed in terms of the distance slipped, the location of rupture or (although much harder to identify) plastic elongation.

\subsubsection{Response of surface support elements (shotcrete, mesh and thin spray-on liner) to dynamic loading}

Again, Sirovision can be used to calculate the permanent deformation of surface support elements through comparison of three dimensional point locations on the test wall before and after each successive blast. Also, detailed fracture mapping of shotcrete is undertaken as well as qualitative measurement of adhesion by assessing shotcrete "druminess".

\subsubsection{Assessment of loss of functionality of the support system}

Qualitative assessment of the in situ performance of each ground support system is based upon the degree of remaining functionality of the system, following each blast. This approach was employed during the Geomechanics Research Centre's Canadian Rockburst Research Program (Tannant and McDowell, 1995). The Support Damage Scale (SDS - see Table 4 at the end of this paper) was used during this research to assess the performance of installed ground support following damaging rockbursts. To date, the SDS has been used in this project. It may, however, need to be modified to suit new and innovative ground support products when they are tested in the future.

Because support damage varies over the supported area, distributions of ground support performance can be generated by assessing the SDS rating at grid points over the test wall for which a PPV is known. PPV contouring between sensors is used to estimate a ground motion value at these grid points. This approach was employed successfully to analyse data from previous simulated rockburst trials on bonded support systems at INCO in Canada (Espley et al. 2002).

\subsection{Blasting Details}

The simulated rockburst blasts are designed to reproduce the dynamic loading associated with a seismic event. This can be achieved by maximising the release of shock wave energy and minimising the effects of rapidly expanding gases.

The potential for generating a significant shear wave improves with the use of an explosive for which the velocity of detonation (VOD) is less than the P-wave propagation velocity in the surrounding rock (Hildyard and Milev, 2001). However, low VOD explosives typically release more energy through the rapid expansion of gas than through shock effects. For this reason, emulsion products are considered to be the most suitable blasting agent. It is preferable to not use
ANFO for the simulated rockburst experiments as the effects of rapidly expanding blast gasses may result in the ejection of rock and support materials from the test wall, potentially compromising the test results. Ultimately, however, the explosive used for the experiments is often dependent on the blasting products available at each mine site.

Details of the blasts conducted at simulated rockburst sites are presented in Tables 1, 2 and 3. The tables show approximate charge lengths and mass of explosive required in a 76 $\mathrm{mm}$ borehole for a pumped emulsion, a packaged emulsion and ANFO. These types of explosives are commonly available in Western Australian mines. The maximum PPV in these tables were estimated based on the equations presented in Ouchterlony (1993):

$$
\mathrm{v}_{\max }=\mathrm{a}_{1}\left(\frac{R}{\sqrt{f_{1}\left(\frac{R}{L_{e}}\right) Q}}\right)^{-b_{2}}
$$

Where the function:

$$
\mathrm{f}_{1}\left(\frac{\mathrm{R}}{\mathrm{L}_{\mathrm{e}}}\right)=\frac{\arctan \left(\mathrm{L}_{\mathrm{e}} / 2 \mathrm{R}\right)}{\mathrm{L}_{\mathrm{e}} / 2 \mathrm{R}}
$$

Where:

$\mathrm{V}_{\max }$ is the maximum expected PPV $(\mathrm{mm} / \mathrm{s})$;

$\mathrm{R}$ is the distance from the source $(\mathrm{m})$;

Q is the charge weight $(\mathrm{kg})$;

$\mathrm{L}_{\mathrm{e}} \quad$ is the charge length (m); and

$a_{1}$ and $b_{2}$ are mine dependent constants related to rockmass attenuation.

Also, if the diameter of the charge is smaller than the diameter of the charge hole, the degree of coupling is defined as:

$$
\mathrm{f}_{\mathrm{eh}}=\phi_{\mathrm{e}} / \phi_{\mathrm{h}}
$$

Where $\phi_{\mathrm{e}}$ is the diameter of the charge and $\phi_{\mathrm{h}}$ is the diameter of the hole. The corrected velocity is then:

$$
\mathrm{v}_{\text {max corrected }}=\mathrm{v}_{\max } \mathrm{f}_{\text {eh }}^{1.5}
$$

This approach takes into consideration the effects of a linear charge of defined length, the type of explosive used, the rock type, rockmass condition and confinement effects relating the diameter of the blasthole to that of the charge. For the values presented in Tables 1, 2 and 3, the two rockmass dependant constants $\left(a_{1}\right.$ and $\left.b_{2}\right)$ were set at 698 and 0.74 respectively, the same values used by Ouchterlony (1993) for a Precambrian granite, since the first two series of simulated rockburst experiments was conducted within felsic intrusions.

Based on these calculations, it is apparent that it becomes impractical to use ANFO in a $76 \mathrm{~mm}$ hole for the $5 \mathrm{~m} / \mathrm{s}$ blast, since the charge length becomes greater than the expected length of the test section $(10 \mathrm{~m})$. Generating $5 \mathrm{~m} / \mathrm{s}$ PPV over such a large length of the cross-cut increases the likelihood of severe damage which may restrict re-entry and prevent full analysis of the results. Also, while the distance between the blastholes and the test wall may be decreased to reduce the amount of explosive required, this may cause damage due to gas expansion, which would adversely affect the results.

\section{THE LONG SHAFT SIMULATED ROCKBURSTS}

\subsection{Mine Description}

Long Shaft is situated near Kambalda, Western Australia, approximately $600 \mathrm{~km}$ east of Perth. The Long orebody was first discovered in December 1971. Shaft sinking commenced in 1975 and was completed to a depth of $936 \mathrm{~m}$. 
TABLE 1 Approximate charge details for simulated rockbursts using pumped emulsion (Orica 2500 Powerbulk Emulsion)

\begin{tabular}{|l|c|c|c|c|}
\cline { 2 - 5 } \multicolumn{1}{c|}{} & \multicolumn{4}{c|}{ Blast Number } \\
\cline { 2 - 5 } \multicolumn{1}{c|}{} & Calibration & 1 & 2 & 3 \\
\hline Location & Mid height & Mid height & Upper & Lower \\
\hline Target PPV (m/s) & $\sim 0.01$ & 0.5 & 1.5 & 5 \\
\hline $\begin{array}{l}\text { Approx. Mass of } \\
\text { Pumped Emulsion } \\
\text { Required (kg) }\end{array}$ & $\begin{array}{c}0.25 \mathrm{~kg} \\
\text { Primer }\end{array}$ & 8 & 16 & 44 \\
\hline $\begin{array}{l}\text { Approximate Charge } \\
\text { Length Required }(\mathrm{m}) \\
\text { (76 mm borehole) }\end{array}$ & $\begin{array}{c}0.25 \mathrm{~kg} \\
\text { Primer }\end{array}$ & 1 & 3 & 8 \\
\hline
\end{tabular}

TABLE 2 Approximate charge details for simulated rockbursts using packaged emulsion (Dyno Nobel Powermite Advance $65 \mathrm{~mm} \times 400 \mathrm{~mm}$ Cartridges)

\begin{tabular}{|l|c|c|c|c|}
\cline { 2 - 5 } \multicolumn{1}{c|}{} & \multicolumn{4}{c|}{ Blast Number } \\
\cline { 2 - 5 } \multicolumn{1}{c|}{} & Calibration & 1 & 2 & 3 \\
\hline Location & Mid height & Mid height & Upper & Lower \\
\hline Target PPV (m/s) & $\sim 0.01$ & 0.5 & 1.5 & 5 \\
\hline $\begin{array}{l}\text { Approx. Mass of } \\
\text { Packaged Emulsion } \\
\text { Required (kg) }\end{array}$ & $\begin{array}{c}0.25 \mathrm{~kg} \\
\text { Primer }\end{array}$ & 8 & 18 & 63 \\
\hline $\begin{array}{l}\text { Approximate Charge } \\
\text { Length Required }(\mathrm{m}) \\
(76 \text { mm borehole) }\end{array}$ & $\begin{array}{c}0.25 \mathrm{~kg} \\
\text { Primer }\end{array}$ & 1.5 & 3.5 & 12 \\
\hline
\end{tabular}

TABLE 3 Approximate charge details for simulated rockbursts using ANFO

\begin{tabular}{|l|c|c|c|c|}
\cline { 2 - 5 } \multicolumn{1}{c|}{} & \multicolumn{4}{c|}{ Blast Number } \\
\cline { 2 - 5 } \multicolumn{1}{c|}{} & Calibration & 1 & 2 & 3 \\
\hline Location & Mid height & Mid height & Upper & Lower \\
\hline Target PPV (m/s) & $\sim 0.01$ & 0.5 & 1.5 & 5 \\
\hline $\begin{array}{l}\text { Approx. Mass of } \\
\text { Packaged Emulsion } \\
\text { Required (kg) }\end{array}$ & $\begin{array}{c}0.25 \mathrm{~kg} \\
\text { Primer }\end{array}$ & 7 & 18 & 73 \\
\hline $\begin{array}{l}\text { Approximate Charge } \\
\text { Length Required }(\mathrm{m}) \\
\text { (76 mm borehole) }\end{array}$ & $\begin{array}{c}0.25 \mathrm{~kg} \\
\text { Primer }\end{array}$ & 2 & 5 & 20 \\
\hline
\end{tabular}

Seismicity at Long Shaft is primarily due to the high stress field causing failure of the strong footwall rock and stiff porphyry intrusions. These failure mechanisms include stress fracturing of intact rock and (stress related) movement of rock along existing discontinuities. Failure of intact rock can be in the form of strain bursting, especially in porphyry dykes and siliceous basalt, and aseismic creep failure of talccarbonate ultramafic hangingwall rocks. Crushing of intact rock in the top corner of deep excavations and slabbing of the walls and backs in deep excavations are also common. Porphyry intrusions (greater than $20 \mathrm{~m}$ thick) have been left unmined as regional stability pillars in many areas of the mine, exacerbating stress failure and mine seismicity in those areas (Heal 2001).

Ground support design at Long Shaft in these seismically active zones reflects the anticipated level of dynamic loading and has been based on energy demand methods. However, there are limited records or analysis of the performance of the typical mine ground support systems under strong dynamic loading.

\subsection{Specific Aims and Layouts}

Quantitative data on the performance of ground support systems under a range of dynamic loads was desired to give more confidence in ground support selection and design. Two sites were chosen for conducting the simulated rockbursts, with two ground support systems per site.

The testing layout at the first site (the $13 / 2$ Access at $660 \mathrm{~m}$ depth, April 2004) is shown in Figure 6. The ground support systems tested were:

Ground Support System 1: "Dynamic Support"

- $75 \mathrm{~mm}$ thick fibrecrete (steel fibres)

- Mine Standard Mesh

- $1 \mathrm{~m}$ by $1.2 \mathrm{~m}$ pattern, $2.4 \mathrm{~m}$ long SS46 Split Sets

- $1 \mathrm{~m}$ by $1.5 \mathrm{~m}, 2.4 \mathrm{~m}$ long Cone Bolts (grouted)

Ground Support System 2: "High Density Split Sets"

- $75 \mathrm{~mm}$ thick fibrecrete (steel fibres)

- Mine Standard Mesh 13m

- $0.6 \mathrm{~m}$ by $0.6 \mathrm{~m}$ pattern, $2.4 \mathrm{~m}$ long SS46 Split Sets

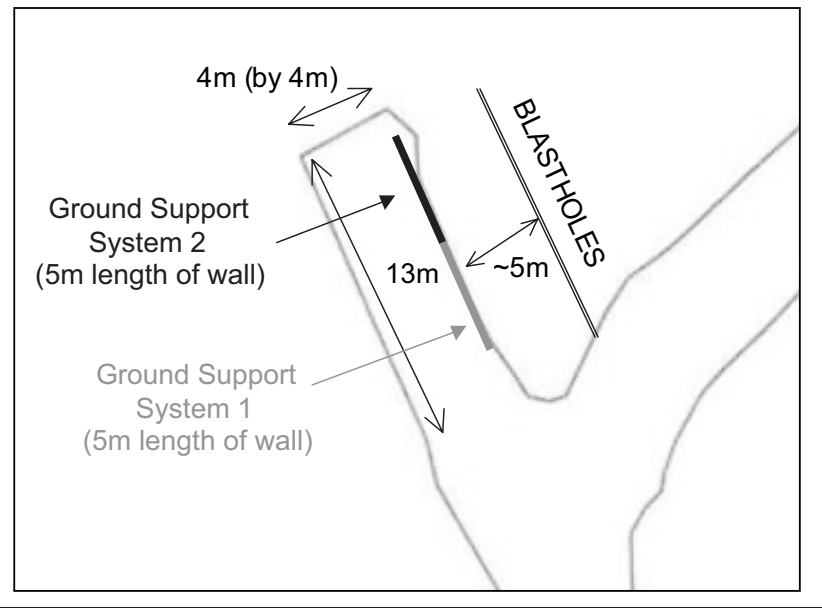

FIG. 6 Long Shaft Site 1 Simulated Rockbursts testing layout

The testing layout at the second site (Rhondo North at 600 $m$ depth, June 2004) is shown in Figure 7. The ground support systems tested were:

Ground Support System 3: "Ore Drives"

- Mine Standard Mesh

- $1 \mathrm{~m}$ by $2 \mathrm{~m}$ pattern, $2.4 \mathrm{~m}$ long SS46 Split Sets

Ground Support System 4: "Upgraded Ore Drives"

- Mine Standard Mesh

- $1 \mathrm{~m}$ by $1 \mathrm{~m}$ pattern, $2.4 \mathrm{~m}$ long SS46 Split Sets

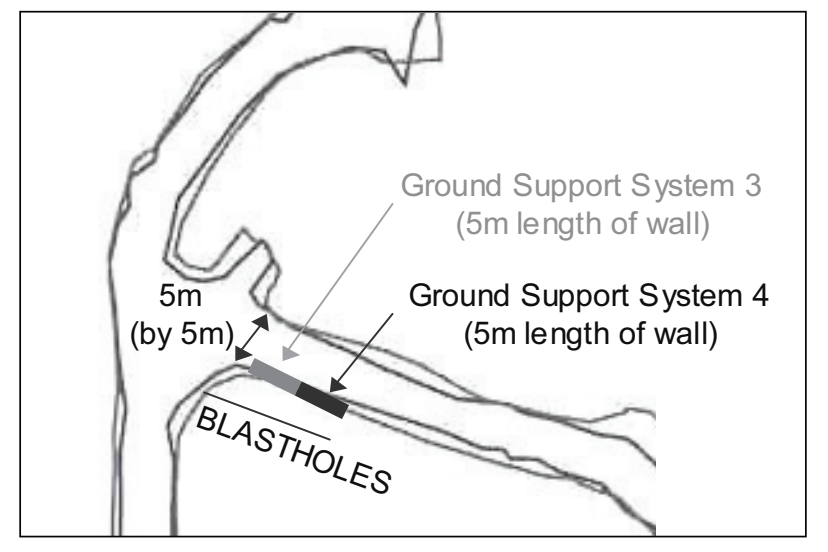

FIG. 7 Long Shaft Site 2 Simulated Rockbursts testing layout 
TABLE 4 The Geomechanics Research Centre Support Damage Scale (SDS) after Tannant and McDowell, 1995

\begin{tabular}{|c|c|c|c|}
\hline $\begin{array}{l}\text { Damage } \\
\text { Level }\end{array}$ & General Description & Support Damage & Shotcrete Damage \\
\hline So & Conditions unchanged & No new damage or loading & No new damage or loading \\
\hline S1 & $\begin{array}{l}\text { Support undamaged but } \\
\text { first signs of distress } \\
\text { detectable }\end{array}$ & No damage to any support component & $\begin{array}{l}\text { Shotcrete shows new cracks, very } \\
\text { fine or widely distributed }\end{array}$ \\
\hline S2 & $\begin{array}{l}\text { Slight damage to support } \\
\text { Loading clearly evident } \\
\text { but full functionality } \\
\text { maintained }\end{array}$ & $\begin{array}{l}\text { Plates and wooden washers on some rockbolts are } \\
\text { deformed, showing loading } \\
\text { Individual strands in mesh broken } \\
\text { Mesh bagged but retains material well }\end{array}$ & $\begin{array}{l}\text { Shotcrete cracked, minor flakes } \\
\text { dislodged } \\
\text { Shotcrete is clearly taking load } \\
\text { from broken rockmass (mostly } \\
\text { drummy) }\end{array}$ \\
\hline S3 & $\begin{array}{l}\text { Moderate damage to } \\
\text { support } \\
\text { Support shows significant } \\
\text { loading and local loss } \\
\text { of functionality; retain- } \\
\text { ing function primarily } \\
\text { lost (except in laced or } \\
\text { shotcreted areas) }\end{array}$ & $\begin{array}{l}\text { Plates, wooden washers, and wood blocking on } \\
\text { rockbolts are heavily deformed, showing significant } \\
\text { loading; bolt heads may be "sucked" into rock } \\
\text { Mesh torn near bolt heads with some strands broken } \\
\text { and mesh torn or opened at overlapping edges } \\
\text { Moderate bagging of mesh and isolated failures of } \\
\text { rockbolts } \\
\text { Cable lacing performs well }\end{array}$ & $\begin{array}{l}\text { Shotcrete fractured, often } \\
\text { debonded from rock and/or } \\
\text { reinforcement } \\
\text { Major flakes possibly dislodged } \\
\text { Holding elements mostly intact }\end{array}$ \\
\hline S4 & $\begin{array}{l}\text { Substantial damage to } \\
\text { support } \\
\text { More extensive loss of } \\
\text { retaining and holding } \\
\text { functions (except for lacing } \\
\text { systems) }\end{array}$ & $\begin{array}{l}\text { Mesh is often torn and pulled over rockbolt plates; if it } \\
\text { did not fail, it is substantially bagged (at capacity) } \\
\text { Many rockbolts failed } \\
\text { Rock ejected between support components } \\
\text { Cable lacing is heavily loaded with bagged mesh }\end{array}$ & $\begin{array}{l}\text { Shotcrete heavily fractured and } \\
\text { broken, often separated from the } \\
\text { rockmass with pieces lying on the } \\
\text { ground or hanging from reinforce- } \\
\text { ment (Connections to holding } \\
\text { elements often failed or holding } \\
\text { elements failed locally) }\end{array}$ \\
\hline S5 & $\begin{array}{l}\text { Severe damage to support } \\
\text { Support retaining, holding, } \\
\text { and reinforcing functions } \\
\text { failed }\end{array}$ & $\begin{array}{l}\text { Most ground support components broken or damaged } \\
\text { Most rockbolts fail and rock peels off cable bolts } \\
\text { Shotcrete non-functional } \\
\text { Mesh without cable lacing heavily torn and damaged } \\
\text { Cable lacing systems heavily stressed and often failed }\end{array}$ & $\begin{array}{l}\text { For damage level } \mathrm{S} 5 \text {, shotcrete } \\
\text { fails to be functional and the } \\
\text { left-hand column applies }\end{array}$ \\
\hline
\end{tabular}

Notes:

1) The damage indicators listed in this table describe damage that is new and was caused by the rockburst. If the observer cannot ascertain that the damage was inflicted by the rockburst then the damage should be ignored for the purposes of damage classification.

2) One or more damage scales may be observed in same section and should be recorded separately.

3) Rock and support damage levels need not correspond.

4) Because the function of shotcrete support is somewhat different and more complex than for other support systems, a separate column of indicators is provided over the range of S0 to S4. It is important to record where shotcrete is present and when it has been used to determine the support damage level.

5) Failure of rockbolt applies to failure of nut, plate, anchor or shank.

6) From: Kaiser, P. K., Tannant, D. D., McCreath, D. R. \& Jesenak, P. 1992, 'Rockburst damage assessment procedure', Rock Support in Mining and Underground Construction, eds. Kaiser \& McCreath, Balkema, Rotterdam, pp. 639-647. 
A $1 \mathrm{~m}$ length of ground support system 3, closest to the intersection, had also been sprayed with shotcrete of $75-125 \mathrm{~mm}$ thickness.

A photograph of Site 1, before the first simulated rockburst, is shown in Figure 8. The surface mounted geophones, Sirovision control points and the two ground support systems tested are visible.

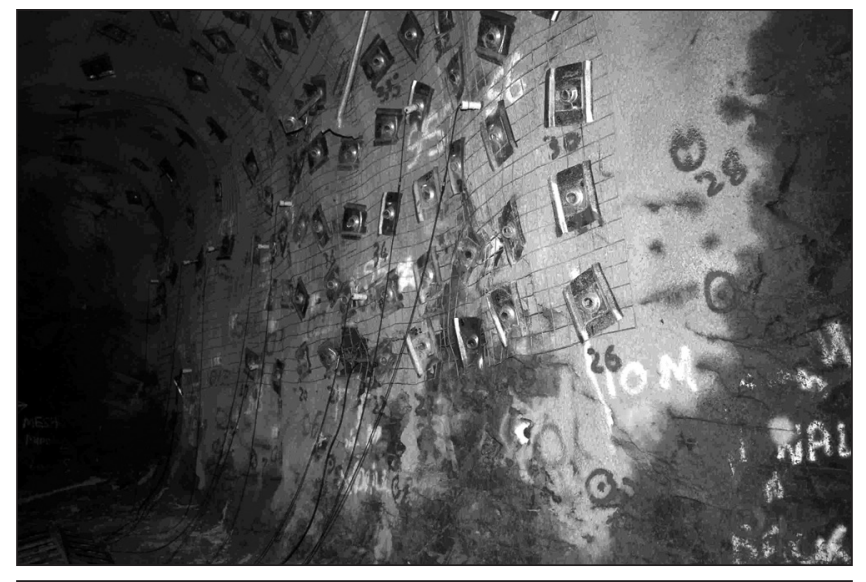

FIG. 8 Long Shaft Site 1 prior to the first simulated rockburst

At both sites, Dyno Nobel Powermite Advance packaged emulsion ( $65 \mathrm{~mm}$ by $400 \mathrm{~mm}$ cartridges) was used for the three simulated rockbursts, with blast design as per Table 2. A conservative approach was taken for Blast 3 at Site 1, where the blast design was chosen to generate a PPV of $3 \mathrm{~m} / \mathrm{s}$ on the test wall. A minimum uncharged length of $3 \mathrm{~m}$ was chosen to limit damage in the vicinity of the blasthole collars.

\subsection{Preliminary Results}

All 6 simulated rockbursts yielded good results, with good performance from the monitoring equipment. The exception was Blast 3 at Site 2, during which loss of $240 \mathrm{~V}$ power to the Impulse monitoring system occurred. PPV's due to this blast had to be estimated using the equations in Section 2.4.

For the ground support systems tested, the Support Damage Scale (SDS) shown in Table 4 was utilised for quantitative damage assessment. Measured PPV's and a general damage assessment from Site 1 are shown in Table 5.

TABLE 5 Long Shaft Site 1 geophone PPV measurements and general damage assessment

\begin{tabular}{lll}
\hline \# & $\begin{array}{l}\text { PPV Range } \\
(\mathrm{m} / \mathrm{s})\end{array}$ & General Damage Assessment \\
\hline 1 & $0.35-0.79$ & $\begin{array}{l}\text { No change to first signs of distress } \\
\text { detectable (S0 - S1) } \\
\text { Very minor cracking of Fibrecrete, both } \\
\text { support systems maintained functionality. }\end{array}$ \\
\hline 2 & $0.42-0.80$ & $\begin{array}{l}\text { No change to first signs of distress } \\
\text { detectable (S0 - S1) } \\
\text { Very minor cracking of Fibrecrete, both } \\
\end{array}$ \\
& \begin{tabular}{l} 
support systems maintained functionality. \\
\hline 3
\end{tabular}$\quad 0.49-2.41$ & $\begin{array}{l}\text { Slight to moderate damage (S2 - S3) } \\
\text { Some cracking of Fibrecrete, some sections of } \\
\text { Fibrecrete debonded, some bulking (contained } \\
\text { by both ground support systems), both } \\
\text { support systems lost some functionality but } \\
\text { retained the rockmass. }\end{array}$ \\
\hline
\end{tabular}

Ground support systems 1 and 2 were capable of withstanding the dynamic loads generated by all three blasts at Site 1 . Borehole camera observations after the final blast showed the rockmass sustained heavy damaged, with the number and width of fractures increased in all 20 observation holes.

The general damage assessment and PPV measurements for the second site are shown in Table 6.

TABLE 6 Long Shaft Site 2 geophone PPV measurements and general damage assessment

\begin{tabular}{lll}
\hline \# & $\begin{array}{l}\text { PPV Range } \\
\text { (m/s) }\end{array}$ & General Damage Assessment \\
\hline 1 & $0.26-1.36$ & $\begin{array}{l}\text { No change to slight damage to support } \\
\text { (S0 - S2) }\end{array}$ \\
& & $\begin{array}{l}\text { Cracking of shotcrete, some bulking, slight } \\
\text { bagging of mesh. Some loss of adhesion } \\
\text { ("drumminess") of shotcrete. Both support }\end{array}$ \\
& systems retained functionality. \\
\hline 2 & $0.10-1.05$ & $\begin{array}{l}\text { No change to slight damage to support } \\
\text { (S0 - S2) }\end{array}$ \\
& $\begin{array}{l}\text { Cracking of shotcrete, further loss of shotcrete } \\
\text { adhesion. Both support systems retained } \\
\text { functionality. }\end{array}$ \\
\hline 3 & $2.7-5.1$ & $\begin{array}{l}\text { Moderate to severe damage with complete } \\
\text { (estimated) } \\
\text { failure of support systems (S3- S5) } \\
\text { Complete failure of support system 4. A 1 } \\
\text { m length of the shotcreted area of support } \\
\text { system 3 retained the rockmass but largely } \\
\text { lost functionality. Approximately 180t of rock } \\
\text { ejected. }\end{array}$ \\
\hline
\end{tabular}

During blast 3 at Long Shaft Site 2, a large failure thickness $(\sim 2.4 \mathrm{~m})$ allowed generation of very high energy demands (greater than $50 \mathrm{~kJ} / \mathrm{m}^{2}$ ) on the failed section of both ground support systems. Failure occurred along a pre-existing flat dipping structure. This demonstrates the variability over short distances that in situ conditions can cause in energy demand on ground support during a rockburst. A photograph of Site 2 after the third simulated rockburst is shown in Figure 9.

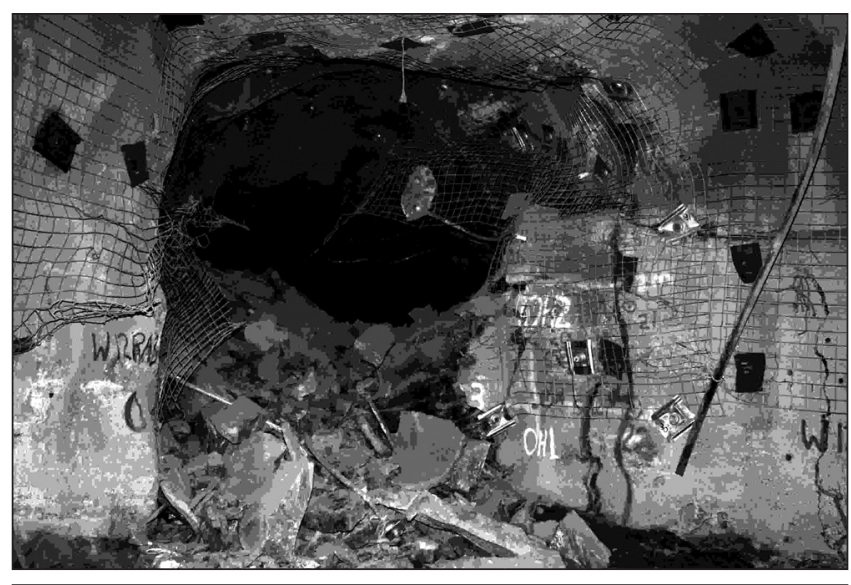

FIG. 9 Damage due to the third simulated rockburst at Long Shaft Site 2 


\subsection{Preliminary Data Analysis}

Peak particle velocity, failure thickness, test wall surface displacement data and qualitative damage assessment using the Support Damage Scale were used in a preliminary analysis of support system performance. Each test wall was separated into individual data points using a $0.5 \mathrm{~m}$ grid. PPV measurements from surface mounted geophones were then contoured. A photo mosaic of the first blast at the second test site ("Ore Drives") with PPV contours overlaid is shown in Figure 10

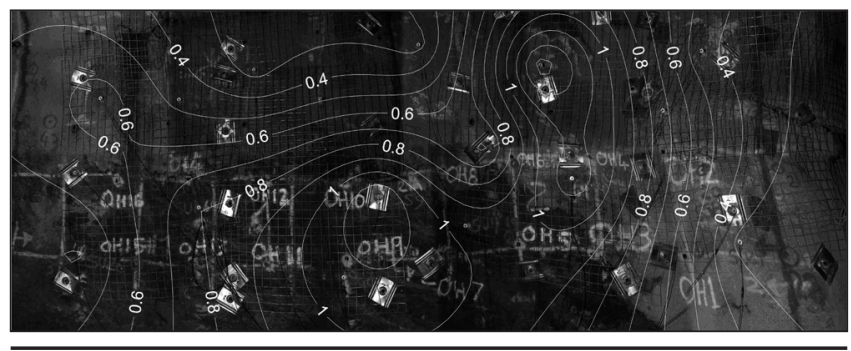

FIG. 10 Photo mosaic showing PPV contours due to the first blast at Long Shaft Site 2

Energy demand on ground support was calculated based on energy methods described in Kaiser et. al (1995), whereby:

$$
\text { Energy demand per square metre }=\frac{1}{2} \mathrm{t} \rho \mathrm{v}^{2}
$$

where $t$ is the thickness of failed rock behind the excavation surface $(\mathrm{m})$ as measured in the nearest borehole camera observation hole, $\rho$ is the rock density $\left(\mathrm{kg} / \mathrm{m}^{3}\right)$ and $\mathrm{v}$ is the PPV as measured by the geophones. Note that a gravity component is not included in this equation since rock ejection is from the wall of the excavation.

Using data from all blasts and for each ground support system tested, grid squares having the same Support Damage Scale rating are grouped together. A summary of the performance of each ground support system is shown in Tables 7 to 10, using both energy demand and PPV.

TABLE 7 Performance summary of ground support system "Dynamic Support" (60 grid squares)

\begin{tabular}{|c|c|c|c|c|c|}
\hline & SDS & So & S1 & S2 & S3 \\
\hline \multirow{3}{*}{ 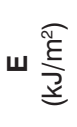 } & Min. & 0.03 & 0.06 & 0.19 & 0.40 \\
\hline & Ave. & 0.12 & 0.24 & 0.30 & 2.77 \\
\hline & Max. & 0.34 & 0.60 & 0.67 & 5.69 \\
\hline \multirow{3}{*}{ ฉ $\frac{\text { n }}{\underline{\varepsilon}}$} & Min. & 0.40 & 0.40 & 0.60 & 0.70 \\
\hline & Ave. & 0.49 & 0.65 & 0.68 & 1.61 \\
\hline & Max. & 0.80 & 0.80 & 1.00 & 2.40 \\
\hline
\end{tabular}

TABLE 8 Performance summary of ground support system "High Density Split Sets" (48 grid squares)

\begin{tabular}{|c|c|c|c|c|}
\hline & SDS & so & S1 & S2 \\
\hline \multirow{3}{*}{ 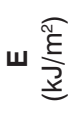 } & Min. & 0.02 & 0.11 & 1.82 \\
\hline & Ave. & 0.13 & 0.99 & 2.52 \\
\hline & Max. & 0.65 & 2.69 & 3.23 \\
\hline \multirow{3}{*}{ ฉ $\frac{\widehat{n}}{\underline{\varepsilon}}$} & Min. & 0.35 & 0.40 & 1.30 \\
\hline & Ave. & 0.47 & 1.07 & 1.65 \\
\hline & Max. & 0.90 & 2.00 & 2.00 \\
\hline
\end{tabular}

TABLE 9 Performance summary of ground support system "Ore Drives" (42 grid squares)

\begin{tabular}{|c|c|c|c|c|c|}
\hline & SDS & So & $\mathrm{S} 1$ & S2 & S5 \\
\hline \multirow{3}{*}{ 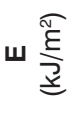 } & Min. & 0.01 & 0.05 & 0.26 & 7.26 \\
\hline & Ave. & 0.15 & 0.29 & 0.52 & 37.31 \\
\hline & Max. & 0.54 & 0.81 & 0.76 & 80.70 \\
\hline \multirow{3}{*}{ aे $\frac{\widehat{n}}{\underline{\xi}}$} & Min. & 0.10 & 0.30 & 0.70 & 3.00 \\
\hline & Ave. & 0.51 & 0.67 & 0.87 & 4.10 \\
\hline & Max. & 1.10 & 1.00 & 1.00 & 5.00 \\
\hline
\end{tabular}

TABLE 10 Performance summary of ground support system "Upgraded Ore Drives" (42 grid squares)

\begin{tabular}{|c|c|c|c|c|c|c|c|}
\hline & SDS & so & S1 & S2 & S3 & S4 & S5 \\
\hline \multirow{3}{*}{ 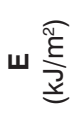 } & Min. & 0.00 & 0.02 & 0.24 & 6.79 & 11.05 & 10.46 \\
\hline & Ave. & 0.19 & 0.28 & 0.56 & 8.98 & 12.45 & 41.28 \\
\hline & Max. & 0.81 & 0.67 & 0.94 & 11.05 & 13.57 & 80.70 \\
\hline \multirow{3}{*}{ ฉે } & Min. & 0.10 & 0.20 & 0.60 & 2.90 & 3.70 & 3.60 \\
\hline & Ave. & 0.55 & 0.68 & 0.97 & 3.33 & 3.93 & 4.31 \\
\hline & Max. & 1.10 & 1.00 & 1.30 & 3.70 & 4.10 & 5.00 \\
\hline
\end{tabular}

Performance data is shown in graphical form in Figures 11 to 14 .

Preliminary data analysis has indicated that the high density pattern of split sets out-performed the dynamic support system, at Long Shaft Site 1. This is thought to be due to the fact that the tight spacing of bolts on the "High Density Split Sets" side of the test wall facilitated greater energy transfer to the bolts themselves. On the "Dynamic Support" side, the larger spacing may have led to higher dynamic loads on the surface support between bolts and fracturing of fibrecrete, which led to a higher SDS rating.

Being the first site for this series of simulated rockbursts, a conservative blast design was used at Long Shaft Site 1. It is hoped that future testing of cone bolts will allow testing at higher energy levels than those achieved in Site 1.

At Long Shaft Site 2, the "Upgraded Ore Drives" ground support system slightly out-performed the "Ore Drives" system. It should be noted that the section of "Upgraded Ore Drives" which survived the third blast had a coating of shotcrete of up to $125 \mathrm{~mm}$ thickness. However, the survival of this section appears due to the fact that the failure thickness here was only $0.6 \mathrm{~m}$, compared to up to $2.4 \mathrm{~m}$ in some areas, therefore the energy demand was lower. Energy demands on some sections of ground support generated during the third blast at Long Shaft Site 2 (up to $80.7 \mathrm{~kJ} / \mathrm{m}^{2}$ ) are considered to be greater than what can be contained by any practical ground support system.

Figures 13 and 14 from Long Shaft Site 2 show a lack of data for S3 and S4 damage. This was primarily due to the fact that the second blast did not generate ground velocities as high as were designed for. It is thought that this was due to a faulty or incorrectly labelled detonator, which led to a non-uniform detonation of the explosive column. More detonators per blast will be used at future test sites to prevent this from occurring.

\subsection{Ongoing Analysis}

Data analysis continues on the first two simulated rockburst sites. In particular, the dynamic behaviour of the rockbolts with end-mounted geophones should provide further insight into the damage process during rockbursts. Specifically, the interaction between the rockmass and rockbolt and if this can 

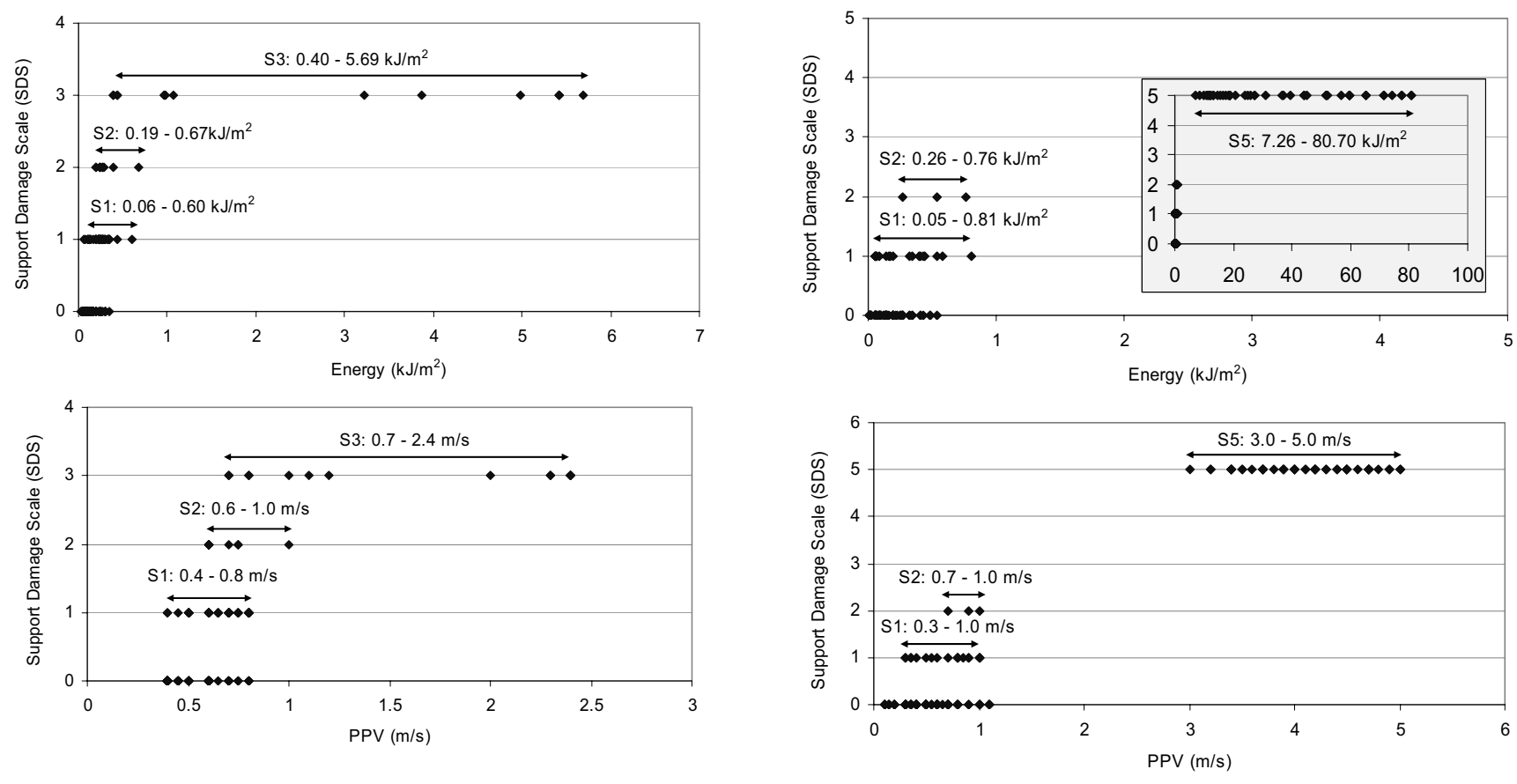

FIG. 11 Performance data for ground support system "Dynamic Support"

FIG. 13 Performance data for ground support system "Ore Drives"
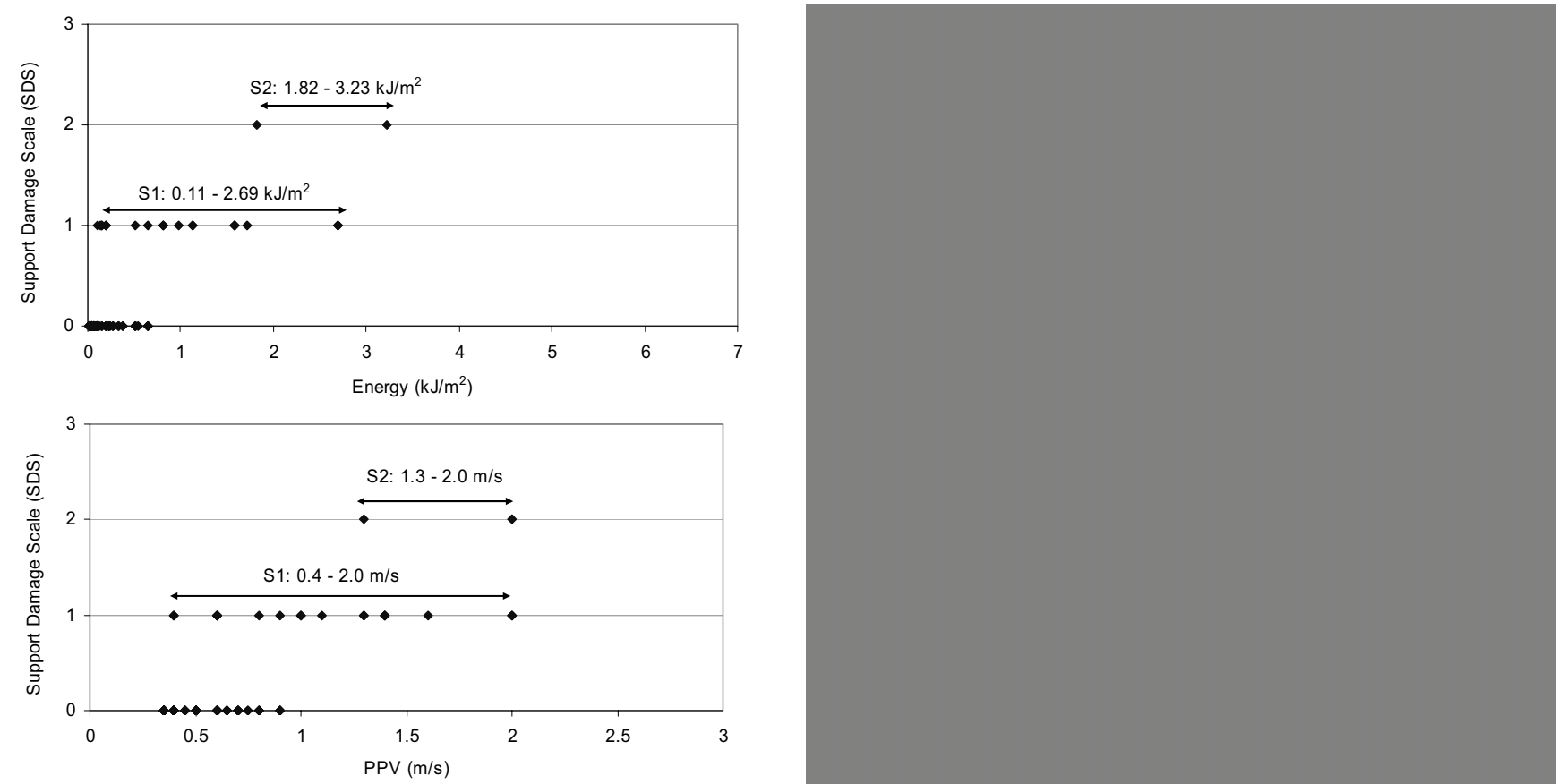

FIG. 12 Performance data for ground support system "High Density Split Sets"

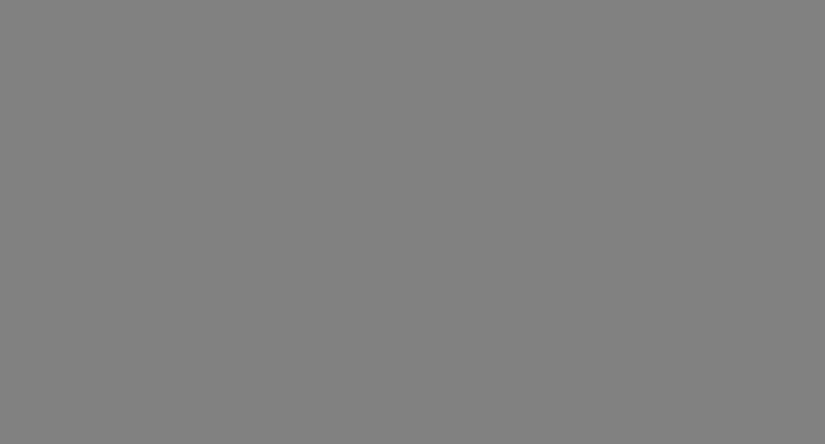

FIG. 14 Performance data for ground support system "Upgraded Ore Drives" 
be used to determine the level of coupling between the two. Also, the behaviour of the rockmass itself will be analysed using the borehole triaxial geophone data and borehole camera findings. The effect of geology and rockmass structure will be included in the findings as data from more simulated rockburst sites becomes available.

Other issues to be considered include the effect of cumulative damage (multiple instances of dynamic loading) and the ability of some heavy ground support systems to prevent the initiation of rock fracture (and hence high dynamic loads).

\section{CONCLUSION}

The four series of simulated rockburst experiments conducted at Long Shaft have demonstrated the suitability of this test method to assess ground support system performance under dynamic loading. The results from the final blast at Long Shaft Site 2 also demonstrated that the testing method can be used to generate extremely high levels of dynamic loading on ground support, when the failure thickness is adequate.

This in situ testing procedure has progressed to a point where test sites can be set up efficiently. Future testing in 2005 is planned at a number of Western Australian mine sites. These tests will include both standard mine ground support systems and innovative systems such as thin spray-on liner products and dynamic cables.

This paper has presented some specific results from the Long Shaft mine, for a particular rockmass and for a particular quality of ground support installation. As more simulated rockburst experiments are conducted, the influence of these variables will be investigated. By incorporating data from above ground testing of ground support and rockburst case histories from around the world, it is intended that this research will give insight into more robust ground support design and selection methods, allowing safety and potentially cost improvements at underground mines affected by rockbursting.

\section{ACKNOWLEDGMENTS}

Funding for this project was provided through the Mine Seismicity and Rockburst Risk Management project at the Australian Centre for Geomechanics. This project is financially supported by Agnico Eagle Mines Ltd, Barrick Gold of Australia, Gold Fields Australia Pty Ltd, Harmony Gold Australia Ltd, Independence Gold, Kalgoorlie Consolidated Gold Mines Pty Ltd, Minerals and Energy Research Institute of Western Australia, MPI Mines Ltd, Perilya Mines Pty, Placer Dome Asia Pacific, and WMC Resources Ltd.

The keen efforts of all the staff at Long Shaft in preparing the test sites and participating in the simulated rockburst experiments are greatly appreciated. Their enthusiasm and interest in the testing was a key factor in its success.

The authors also wish to thank Alex Milev, David Ortlepp, Dwayne Tannant, George Poropat, Gordon Sweby, John Heilig, Ken Pattrick, Olaf Goldbach, Steve Spottiswoode and Steve Webber for the advice they provided.

\section{REFERENCES}

Archibald, J.F., Baidoe, J.P. and Katsabanis, P.T. (2003) Comparative assessment of conventional support systems and spray-on rock linings in a rockburst prone environment. 3rd International Seminar on Surface Support Liners: Thin Spray-on Liners, Shotcrete and Mesh, Quebec City, Canada, 25th - 27th August 2003, Section 20.

CSIRO (2003) Sirovision User Guide - Version 2.5. CSIRO Division of Exploration and Mining.

Espley, S.J., Heilig, J. and Moreau, L.H. (2002) Assessment of the dynamic capacity of liners for application in highly-stressed mining environments at Inco Limited. International Seminar on Surface Support Liners, Johannesburg, South Africa.

Hagan, T.O., Milev, A.M., Spottiswoode, S.M., Hildyard, M.W., Grodner, M., Rorke, A.J., Finnie, G.J., Reddy, N., Haile, A.T., Le Bron, K.B. and Grave, D.M. (2001) Simulated rockburst experiment - an overview. The Journal of The South African Institute of Mining and Metallurgy, August 2001, pp. 217-222.

Haile, A.T. and Le Bron, K. (2001) Simulated rockburst experiment - evaluation of rock bolt reinforcement performance. The Journal of The South African Institute of Mining and Metallurgy, August 2001, pp. 247-251.

Heal, D. (2001) Ground Support in Seismically Active Mines. Unpublished Undergraduate Thesis, The University of Western Australia.

Heal, D., Hudyma, M. and Potvin, Y. (2004) Assessing the in situ performance of ground support systems subjected to dynamic loading. In E. Villaescusa and Y. Potvin (eds), Ground Support 2004, Proceedings of the 5th International Symposium on Ground Support in Mining \& Underground Construction, Perth, 28-30 September 2004, pp. 319-326.

Hildyard, M.W. and Milev, A.M. (2001) Simulated rockburst experiment: Development of a numerical model for seismic wave propagation from the blast, and forward analysis. The Journal of The South African Institute of Mining and Metallurgy, August 2001, pp. 235-245.

Kaiser, P.K., McCreath, D.R. and Tannant, D.D. (1995) Rockburst Support Handbook, Geomechanics Research Centre, Laurentian University, Canada.

Ouchterlony, F. (1993) Blast damage predictions from vibration measurements at the SKB underground laboratories at Äspö in Sweden. 9th Annual Symposium on Explosives and Blasting, San Diego, USA.

Tannant D.D., Brummer R.K. and Kaiser P.K. (1994a) Response of rockbolts to nearby blasts. IV South American Congress on Rock Mechanics, pp 241-248.

Tannant, D.D., Brummer, R.K. and Yi, X. (1995) Rockbolt Behaviour under dynamic loading: field tests and modelling. International Journal of Rock Mechanics and Mining Sciences \& Geomechanics Abstracts, Vol. 32(8), pp. 537-550.

Tannant D.D., McDowell G.M. and McCreath D.R. (1994b) Shotcrete performance during simulated rockbursts. International Workshop on Applied Rockburst Research, Santiago.

Tannant, D.D. and McDowell, G.M. (1995) Monitoring Particle Velocities in Steel Fibre Reinforced Shotcrete at Stobie Mine, GRC internal report. 